\title{
Categorization, Appraisal, and Reporting of Medication Errors Ascertained in Medical Ward of Tertiary Care Hospital
}

\author{
Vinodkumar Mugada', Reethu Chowdary Devineni, Reena Mounika Pendyala, Dilipkumar Vempati, Sarathchandra Kuchi \\ Department of Pharmacy Practice, Aditya Pharmacy College, Surampalem, AP-533437, India.
}

\author{
ARTICLE INFO \\ Article history: \\ Received on: 14/12/2017 \\ Accepted on: 16/03/2018 \\ Available online: 30/05/2018
}

\section{Key words:}

Medication errors, prescribing errors, categorization, prescription.

\begin{abstract}
The purpose of the present study was to categorize, assess and report medication errors. The descriptive crosssectional study was conducted on 377 patients in the department of general medicine for six months. Medication error reporting form (MERF) is used as study instrument. The higher prevalence rate is seen in prescribing errors. Mostly seen prescribing errors were omission of doses, omission of frequency, abbreviated forms, labeling and set of instructions, brand a name and dosage form omission in our study. Medication errors were mostly seen in drugs belonging to the classes of antibiotics, antihypertensive drugs, antipyretics, and diuretics. The possible contributing factors for medication errors in our present study were illegible prescription, failure to adhere to work procedure, peak hour, and abbreviated form, labeling and set of instructions, and miscommunication. Look-alike/sound-alike is the responsible cause of the dispensing centered errors. Education and training to nursing staff, improvement in communication process helps to minimize the prescribing errors.
\end{abstract}

\section{INTRODUCTION}

A medication error was defined as any preventable event that may cause or lead to inappropriate medication use or patient harm when the medication is under the control of the healthcare professional, patient, or consumer (NCC MERP, 2017). Medication errors harm about 15 million people every year and are the main contributors to adverse events to hospitalized patients (Bates et al., 1995; Boyle et al., 1999). Apart from imposing substantial costs between US\$ Six billion and US\$ 29 billion per year, ME's also weakened patients' confidence in medical services. Many errors remain frequently unreported because of the unawareness of voluntary reporting by health care providers (WHO, 2014). Several studies demonstrated the role of specific interventions that might reduce the risk of error (Kaushel et al., 2001), still many hospitals have no system for recording medication errors across healthcare organizations and are thus remained underreported. Despite their high incidence, their reporting is usually done in an

${ }^{*}$ Corresponding Author

Vinodkumar Mugada, Department of Pharmacy Practice, Aditya Pharmacy College, ADB Road, Surampalem, AP-533437, India.

E-mail: mugadavinodkumar18@gmail.com informal manner (Barach and Small, 2000). Verbal discussion of errors at morbidity and/or mortality meetings does not improve patient safety. A formal written report improves patient safety opportunities (Claudia et al., 2002).

Medical wards in government aided general hospitals are usually crowded. The availability of physicians to treat patients is inadequate. Factors like peak hour, unavailability of supporting staff etc will further contribute to the chance of occurrence of medication errors. This will lead to an undesirable therapeutic outcome, adverse drug reactions, and unnecessary expenditure. So, we opted to achieve the following objectives through our study:

a. To identify and categorize medication errors, according to the guidelines of National Coordinating Council for Medication Error Reporting and Prevention (NCCMERP).

b. To analyze the type of outcomes and extent of harm due to medication errors.

c. To assess the possible causes and contributing factors responsible for medication error .

d. To identify the class of drugs causing the major proportion of medication errors. 
e. To identify proper intervention and reporting them in an attempt to minimize them.

\section{MATERIALS AND METHODS}

\section{Study site and study design}

The present study was conducted in the department of general medicine, Government General Hospital, Kakinada for duration of six months. Our present study does not contain any prior hypothesis, data related to medication errors and outcomes are taken at the same time, follow up was not required, all age groups are involved in the study. The above said study characteristics are closely related to characteristic features of descriptive cross-sectional study. So, we have chosen Descriptive Cross-sectional study as our study design.

\section{Ethical considerations}

Permission was approved from Institutional Ethical Committee

(R.C.No./Clinicals/Pharma.D/N2/2017.,Dt 13.03.2017) to conduct this study. The purpose of the study was explained to the patients. The patient consent form was obtained from patients who are willing to co-operate the study.

\section{Sampling technique, Sample size estimation}

\section{Sampling technique}

Sample was collected by using simple random sampling technique. Because random sampling minimizes bias and each member of the population is equally likely to be chosen as a part of the sample. The sample was collected randomly by using the random number method.

\section{Sample size estimation}

The estimated sample size of the present study is $\mathbf{3 7 7}$. The population size was 20,000 , the margin of error is $5 \%$, the confidence level is $95 \%$ and the response distribution was $50 \%$.

Sample size $n$ and margin of error E are given by

$$
\begin{gathered}
\mathrm{X}=\mathrm{Z}\left(\mathrm{C}^{2} / 100\right) r(100-r), \\
\mathrm{M}=\mathrm{N} x /\left((\mathrm{N}-1) \mathrm{E}^{2}+\mathrm{X}\right), \\
\mathrm{E}=\operatorname{Sqrt}[(\mathrm{N}-n) x / n(\mathrm{~N}-1)],
\end{gathered}
$$

where $\mathrm{N}$ is the population size $(20,000), \mathrm{R}$ is fraction of responses that you are interested in and $\mathrm{Z}(\mathrm{C} / 100)$ is the value of confidence level C.

\section{Study Instrument}

Medication error reporting form (MERF) is used as study instrument. This is a blame-free reporting tool of Jawaharlal Institute of Postgraduate Medical Education and Research which holds the data regarding all the demographics of patients and diagnosis. It also embodies the details of medicines and success of description of the event.

The outcomes of medication errors were categorized according to guidelines based on National Coordinating Council for Medication Error Reporting and Prevention. Category ' $A$ ' has the capacity to cause an error. Category ' $\mathrm{B}$ ' means an error occurred but did not reach the patient. Category ' $\mathrm{C}$ ' means error reached the patient but did not cause any harm. Category ' $D$ ' means error should be monitored to confirm that it resulted in no harm to the patient. Category ' $E$ ' contributes to or results in temporary harm to the patient and required intervention. Category ' $F$ ' requires initial or prolonged hospitalization. Category ' $G$ ' contributes to or results in permanent patient harm. Category ' $\mathrm{H}$ ' requires intervention necessary to sustain life. Category ' $\mathrm{I}$ ' contributes to or results in patient's death.

\section{Participants}

- $\quad$ Patients who are admitted to medical ward with any disease.

- $\quad$ Patients in all age groups are included.

- $\quad$ Patients with another concomitant disease along with present diagnosis are included.

- In case of inpatient department patients with a length of stay, more than 2 days are preferred.

\section{Data collection and Data analysis}

\section{Data collection}

Data regarding patient details like age, gender, date and time of event, type of medication errors and the class of drugs causing medication errors were collected from case sheets of patients. The data regarding the outcome of the event was collected by interacting with the patient. Description of event, possible causes, and contributing factors, the done intervention was interpreted from the collected data.

\section{Data analysis}

The mean and standard deviation were calculated for age. Frequency and/or percentages were calculated for qualitative data like the outcome of events, possible causes and contributing factors, description of prescribing errors, class of drugs causing the major proportion of medication errors, type of medication errors and intervention done.

\section{RESULT AND DISCUSSION}

Majority of medication errors were observed in the age group of 40-60 years (Table 1). The mean age of males and females was $49.2 \pm 14.32$ years and $48.9 \pm 15.3$ years, respectively.

Table 1: Age wise distribution of medication errors.

\begin{tabular}{cccc}
\hline Age & Male & Female & Percentage \\
\hline $10-20$ & 8 & 6 & $4 \%$ \\
$20-30$ & 25 & 18 & $11 \%$ \\
$30-40$ & 35 & 23 & $15 \%$ \\
$40-50$ & 54 & 37 & $24 \%$ \\
$50-60$ & 63 & 36 & $28 \%$ \\
$60-70$ & 36 & 22 & $16 \%$ \\
$70-80$ & 4 & 6 & $2 \%$ \\
$>80$ & 2 & 2 & $1 \%$ \\
\hline
\end{tabular}

Of the three type of medication errors, prescribing errors are high in number $(89 \%)$, followed by administration errors $(8 \%)$. The omission of dose (25\%) and omission of frequency $(20 \%)$ were the most commonly observed prescribing errors (Table 2 and Table 3). 
Table 2: Types of medication errors.

\begin{tabular}{ccc}
\hline Type of Errors & Frequency & Percentage \\
\hline Prescribing errors & 334 & $89 \%$ \\
Administration errors & 31 & $8 \%$ \\
Dispensing errors & 12 & $3 \%$ \\
\hline
\end{tabular}

Table 3: Description of prescribing errors.

\begin{tabular}{ccc}
\hline Description of prescribing errors & Frequency & Percentage \\
\hline Dose missing & 108 & $25 \%$ \\
Frequency & 87 & $20 \%$ \\
Abbreviations & 66 & $15 \%$ \\
Labeling and instructions & 66 & $15 \%$ \\
Brand names & 64 & $14.7 \%$ \\
Dosage form & 45 & $10.3 \%$ \\
\hline
\end{tabular}

The possible contributing factors to medication errors (Table 4 ) in our present study were illegible prescription (41\%), failure to adhere to work procedure $(20 \%)$, peak hour $(19 \%)$, an abbreviated form (7\%), labeling and set of instructions (7\%), miscommunication (4\%), and look alike/sound alike $(2 \%)$.

Table 4: Possible causes and contributing factors.

\begin{tabular}{ccc}
\hline Possible causes and contributing factors & Frequency & Percentage \\
\hline Illegible prescription & 377 & $41.3 \%$ \\
Failure to adhere to work procedure & 180 & $19.7 \%$ \\
Peak hour & 171 & $18.7 \%$ \\
Wrong labeling/instruction & 66 & $7.24 \%$ \\
Use of abbreviations & 66 & $7.24 \%$ \\
Miscommunication & 36 & $3.95 \%$ \\
Others & 15 & $1.64 \%$ \\
\hline
\end{tabular}

In the present study, as shown in Table 5 Category D was predominantly observed (44.3\%) followed by Category C $(25 \%)$ and Category A (17\%).

Table 5: Outcome of events.

\begin{tabular}{ccc}
\hline Type of outcome & Frequency & Percentage \\
\hline No harm but requires monitoring & 167 & $44.3 \%$ \\
No harm & 94 & $25 \%$ \\
Events have potential to cause an error & 64 & $17 \%$ \\
Temporary harm requiring treatment & 42 & $11.1 \%$ \\
Temporary harm requiring hospitalization & 10 & $2.6 \%$ \\
\hline
\end{tabular}

In our present study, four types of interventions have been discussed with the physician/nurse/patient wherever applicable. The interventions (shown in Table 6) are as follows Education and training provided (39\%), informed staff who made the error $(34.2 \%)$, Change to correct dose/dosage form, frequency of drug (15.6\%) and communication process improvement (11.1\%).

Of the 30 categories of drugs that are responsible for medication errors (Table 7), the majority of the medication errors were observed with drugs belonging to antibiotics (16.4\%), antihypertensive drugs (13.7\%), and antipyretics (10.87\%).
Table 6: Intervention done.

\begin{tabular}{ccc}
\hline Intervention & Frequency & Percentage \\
\hline Education/training provided & 147 & $39 \%$ \\
Informed staff who made an error & 129 & $34.2 \%$ \\
Changed to correct drug/dose/frequency & 59 & $15.6 \%$ \\
Communication process improved & 42 & $11.1 \%$ \\
\hline
\end{tabular}

Table 7: Medication errors according to class of drugs.

\begin{tabular}{ccc}
\hline Categories & Frequency & Percentage \\
\hline Antibiotics & 62 & $16.4 \%$ \\
Anti hypertensive & 52 & $13.7 \%$ \\
Antipyretics & 41 & $10.87 \%$ \\
Diuretics & 34 & $9.02 \%$ \\
Vitamin supplements & 31 & $8.2 \%$ \\
Anti Ulceratives & 30 & $7.95 \%$ \\
Electrolyte supplements & 29 & $7.42 \%$ \\
NSAIDs & 28 & $7.6 \%$ \\
Anti emetics & 25 & $6.63 \%$ \\
Anti Hyperlipidemics & 23 & $6.1 \%$ \\
Anti epileptics & 22 & $5.8 \%$ \\
Anti diabetics & 20 & $5.30 \%$ \\
Antacids & 13 & $3.4 \%$ \\
Laxatives & 13 & $3.4 \%$ \\
Hepatic protectors & 11 & $2.9 \%$ \\
Haemopoitic agents & 11 & $2.9 \%$ \\
Antimalarials & 10 & $2.65 \%$ \\
Endocrine & 10 & $2.65 \%$ \\
Others & 66 & $17.50 \%$ \\
\hline
\end{tabular}

Similar to our study results, one study reported $75 \%$ medication errors in males (Sheikh et al., 2017). In contrast, two studies reported $67.1 \%$ and $61.8 \%$ of medication errors in females respectively (Agu et al., 2014; Sada et al., 2015). Prescribing errors are described as errors initiated during the prescribing process. Incorrect selection of medication, wrong dose, wrong strength, wrong frequency, incorrect route of administration, inadequate instruction for use of medication and wrong dosage form are examples of prescribing errors (Alsulami et al., 2013). Sada et al. (2013) reported omission errors $(42.89 \%)$, wrong combination (28.13\%) and wrong abbreviation as the most commonly observed prescribing errors. Odukoya et al. (2014) observed wrong drug quantity (40\%), wrong duration of therapy (21\%), wrong dosing instructions (40\%) and wrong dosage formulation (11\%) as the four most common medication errors. Fyhr and Akselsson (2012) observed that $42 \%$ of medication errors occurred was prescribing centered errors. Among them, $45 \%$ are due to prescribing wrong dose. Al-Khani et al. (2014) showed that majority of prescribing errors (53\%) are due to wrong dose. Zakharov et al. (2012) reported wrong dosage $(60.9 \%)$, wrong medication $(19.3 \%)$ and route of administration (12.9\%) as the common prescribing errors. Inexperienced doctors and nurses are found to make more errors (Lesar, 1997; Wilson et al., 1998).

Look-alike/sound-alike is the responsible cause of the dispensing centered errors. Miscommunication, failure leads to 
work adhere procedure, environmental factors are responsible for patient-centered errors and nurse-centered errors. Abbreviated form, brand names, wrong dose, route, dosage form, duration, strength may cause a prescribing error. These medication errors are due to heavy crowded subjects in a hospital, heavy workload, lack of time, lack of staff availability in hospitals. Junior doctors in secondary care contribute the majority of prescribing errors. One study reported that environmental factors, workload, interruptions, working staff pressure and lack of time are perceived as the major cause of medication errors by medical staff (Ryan et al., 2013). One study reported high workload, lack of time, similar confusing names, sole pharmacist as the major causes of dispensing errors that major causes of dispensing errors (Al-arifi, 2014).

Education and training to the staff that made the error is the primary intervention done by the pharmacist. The communication process is a weak sign in some elderly and deaf patients. In such a case, there is occurrence of patient-centered errors as well as nurse-centered errors. In such case communication process must be improved. Frydenberg and Brekke (2012) obtained Category E (20\%) and Category F (27\%) as major outcomes. Our study observed $11.1 \%$ of Category E errors and $2.6 \%$ of Category F errors. Starmer et al. (2017) reduced medical errors and preventable adverse events by implementing handoff programme as an intervention. The medication error rate decreased by $23 \%$ and rate of preventable adverse events decreased by $30 \%$ from the preintervention period to post-intervention period. Poon et al. (2010) reported that the effect of the bar-code eMAR and computerized physician order entry was similar in reducing the serious medication errors. Fabein et al. (2015) found that Computerized Physician Order Entry (CPOE) System led to a significant decrease (92\%) in prescribing errors and to a $17.5 \%$ significant decrease in administration errors. No significant difference was found in regards to dispensing errors. Cousein et al. (2014) implemented automated Drug dispensing system and reduced 53\% of medication administration errors. Wrong dose and wrong drug errors were also reduced by $79.1 \%$ and $93.7 \%$ respectively. Dharmar et al. (2013) observed that pediatric critical care telemedicine consultations significantly reduced the risk of physician-related medication errors in the emergency department. Hou et al. (2013) showed that the coupling of the computerized physician order entry (CPOE) system with the pediatric dosing decision support (PDDS) system effectively detected near misses and reduced dose prescribing errors including potentially fatal errors. The final dosing error rate was significantly reduced to $0.66 \%$.

Most probable diseases occurred in hospital sector was found to be Cardiovascular disorders, infections, electrolyte imbalances. Sada et al. (2015) reported that cardiovascular drugs (33.9\%) and antimicrobial agents $(20.49 \%)$ contributed majority (80\%) of medication errors. Lesar (1997) reported that xanthenes, CVA agents, antimicrobial, and narcotics were more frequently associated with medication errors. Murray et al. (2017) reported a high number of errors with antibiotics.

Medication errors increase the vulnerability of patients to adverse drug events. This, in turn, increases the length of stay for the patient, increases the cost of expenditure for patients, insurance payers, and government organizations. However, these medication errors will take place irrespective of measures of control, might be due to an individual or in the system. So, we have to find the root cause of the error and minimize the risk by implementing interventions.

The individual health care professional like physician, nurse or pharmacist remains an important contributor to patient safety. So trainees should attain expertise to minimize the medication errors (Kozer et al., 2002). Firth-Cozens et al. (2003) studied a number of individual characteristics that affects patient safety. He found that the individual characteristics most likely to affect safety are low-risk perception, sensation seeking, type A behavior (aggressive, competitive and inpatient), high selfesteem, psychological ill health and attitudes concerning safety. Firth-Cozens et al., suggested a need for research in this area and psychometrics can contribute to the recognition of potential difficulties (Firth-Cozens et al., 2003). One study found nine causes or associated factors for medication errors related to the handling of medication. They are insufficient knowledge, uncertainty about procedures, ignorance of sources of error, poorly defined responsibilities, low community spirit, insufficient communication, clinician autonomy and low accept of change, strong professional identity, low priority task and logistic problems (Andersen, 2002). In a study, miscommunication generated diagnostic and treatment errors. $80 \%$ of the errors involved informational and personal miscommunication like among colleagues, between patient and physician, inaccessible medical records, etc (Woolf et al., 2004). So, rather underestimating the potential of medication errors, all health care professionals must develop a good attitude towards reporting medication errors.

The medication error reporting system should be strengthened in developing countries like India. Medication error reporting system helps to identify the serious adverse events and reduces its incidence, helps to achieve patient safety and improve the patient care. This system is in evolving stage in India. It takes certain considerable time and effort for expertise to develop a robust medication error reporting system in India. However, efforts are now being taken in India, to set up a pharmacovigilance system, which can collect information on ADRs. In the recent years, India has seen the establishment of a society for pharmacovogilance, which aims at "establishing pharmacovigilance as a distinct and influential clinical discipline in India" (Society of Pharmacovigilance, 2008). A study found that the national pharmacovigilance center benefited the patients by creating awareness about ADR's. In spite of discouraging factors like mild reaction ADR's, well-known reactions from the patients etc, doctors were interested in continuing the same system, educating the nurse staff, knowing more about rare ADR's in monthly meetings and bringing out a quarterly/monthly bulletin on ADR's (Ramesh and Parthasaradhi, 2009). One study showed that pharmacovigilance improved the reporting of ADR's in the prospective study (3\%) compared to retrospective study $(1 \%)$. Both the studies show that pharmacovigilance encourages meticulous observation of ADR's by doctors and the hospital staff and improved reporting of the same (Gor and Desai, 2004).

\section{CONCLUSION}

It was concluded that prescribing errors are high in number, the errors caused no harm to the patients. Providing education and training to staff, avoiding miscommunication would be beneficial. Use of clinical pharmacist in settings with high 
patient to doctor ratio would be very helpful in minimizing the medication errors and their risk.

\section{FINANCIAL SUPPORT AND SPONSORSHIP}

Nil.

\section{CONFLICT OF INTEREST}

There are no conflicts of interest

\section{REFERENCES}

Andersen SE. Implementing a new drug record system: a qualitative study of difficulties perceived by physicians and nurses. Qual Saf Health Care. 2002; 11:19-24.

Alsulami Z, Conroy S, Choonara I. Medication errors in the Middle East countries: A systematic review of the literature. European Journal of Clinical Pharmacology. 2013; 69(4):995-1008. doi: 10.1007/ s00228-012-1435-y.

Agu K, Oqua D, Adeyanju Z, Alfa Isah M, Adesina A, Ohiaeri S, Ali P, Ekechukwu N, Adah Akpakwu A, Sani T, Onuche Omeh I, King $\mathrm{R}$, Wutoh A. The Incidence and Types of Medication Errors in Patients Receiving Antiretroviral Therapy in Resource-Constrained Settings. PLOS ONE. 2014; 9(1):p.e87338.

Al-Arifi M. Community pharmacists' attitudes toward dispensing errors at community pharmacy setting in Central Saudi Arabia Saudi Pharmaceutical Journal. 2014; 22(3):195-202. doi: 10.1016/j. jsps.2013.05.002.

Al-Khani S, Moharram A, Aljadhey H. Factors contributing to the identification and prevention of incorrect drug prescribing errors in outpatient setting. Saudi Pharmaceutical Journal. 2014; 22(5):429-32.

Bates DW, Boyle D, Vander VM, Schneider J, Leape L. Relationship between medication errors and adverse drug events. J Gen Intern Med. 1995; 10:199-205. https://www.ncbi.nlm.nih.gov/ pubmed/7790981.

Bates DW, Miller EB, Cullen DJ, Burdick L, Williams L, Laird NP, et al. Patient risk factors for adverse drug events in hospitalized patients. ADE Prevention Study Group. Arch Intern Med. 1999; 159(21):2553-60. https://www.ncbi.nlm.nih.gov/pubmed/10573045.

Barach P, Small SD. Reporting and preventing medical mishaps: Lessons from non-medical near miss reporting systems. British Medical Journal. 2000; 320(7237):759-63. https://www.ncbi.nlm.nih.gov/pmc/ articles/PMC1117768/.

Claudia LU, Sharon BS, De VSP, Merrell D, Gail MB. Perceived barriers to medical-error reporting: An exploratory investigation. Journal of Health Care Management. 2002; 47(4):236-79. https://www.ncbi.nlm.nih. gov/pubmed/12221747.

Cousein E, Mareville J, Lerooy A, Caillau A, Labreuche $\mathrm{J}$, Dambre D, et al. Effect of automated drug distribution systems on medication error rates in a short-stay geriatric unit. Journal of Evaluation in Clinical Practice. 2014; 20(5):678-84. doi: 10.1111/jep.12202. Epub 2014 Jun 11.

Dharmar M, Kuppermann N, Romano PS, Yang NH, Nesbitt JP, Nguyen C, Parsapour K, Marcin JP. Telemedicine consultations and medication errors in rural emergency departments. Pediatrics. 2013; 132:1090-1097.

Error. About Medication Errors [Internet]. NCC MERP. 2017 [cited 30 September 2017]. Available from: http://www.nccmerp.org/aboutmedication-errors.

Firth-Cozens J, Cording H, Ginsburg R. Can we select health professionals who provide safer care? Qual Saf Health Care. 2003; 12:16-20.

Frydenberg K, Brekke M. Poor communication on patients' medication across health care levels leads to potentially harmful medication errors. Scandinavian Journal of Primary Health Care. 2012; 30(4):234-40. doi: $10.3109 / 02813432.2012 .712021$.

Fyhr A, Akselsson R. Characteristics of medication errors with parenteral cytotoxic drugs. Eur J Cancer Care (Engl). 2012; 21(5):606-13. doi: 10.1111/j.1365-2354.2012.01331.x.

Gor AP, Desai SV. Adverse drug reactions (ADR) in the inpatients of medicine department of a rural tertiary care teaching hospital and influence of pharmacovigilance in reporting ADR. Indian J Pharmacol. 2008; 40:37-40. doi: 10.4103/0253-7613.40488.

Hou JY, Cheng KJ, Bai KJ, Chen HY, Wu WH, Lin YM, Wu MTM. The effect of a computerized pediatric dosing decision support system on pediatric dosing errors. J Food Drug Anal. 2013; 21(3):286-91.

Hernandez F, Majoul E, Montes-Palacios C, Antignac M, Cherrier B, Doursounian L, Feron J, Robert C, Hejblum G, Fernandez C, Hindlet P. An Observational Study of the Impact of a Computerized Physician Order Entry System on the Rate of Medication Errors in an Orthopaedic Surgery Unit. PLOS ONE. 2015; 10(7):p.e0134101.

Kaushel R, Bates DW, Landrigon C, Mckenna KJ, Clapp MD, Federica F, Goldmann DA. Medication errors and adverse drug events in pediatric inpatients. JAMA. 2001; 285:2114-20. https://www.ncbi.nlm.nih. gov/pubmed/11311101

Kozer E, Scolnik D, Macpherson A, Keays T, Shi K, Luk T, Koren G. Variables associated with medication errors in pediatric emergency medicine. Pediatrics. 2002; 110:737-42. https://www.ncbi.nlm. nih.gov/pubmed/12359787.

Lesar T. Medication-prescribing errors in a teaching hospital. A 9-year experience. Archives of Internal Medicine. 1997; 157(14):1569-76.

Murray KA, Belanger A, Devine LT, Lane A, Condren ME. Emergency department discharge prescription errors in an academic medical center. Proceedings (Baylor UniversityMedicalCenter). 2017; 30(2):143-46. https://www.ncbi.nlm.nih.gov/pmc/articles/PMC5349807/.

Odukoya OK, Stone JA, Chui MA. E-prescribing errors in community pharmacies: exploring consequences and contributing factors. Int J Med Inform. 2014; 83:427-437.

Poon EG, Keohane CA, Yoon CS, Ditmore M, Bane A, Korach OL, Moniz T, Rothschild JM, Kachalia AB, Hayes J, Churchill WW, Lipsitz S, Whittemore AD, Bates DW, Gandhi TK. Effect of Bar-Code Technology on the Safety of Medication Administration. N Engl J Med. 2010; 362:16981707. doi: 10.1056/NEJMsa0907115.

Ramesh M, Parthasarathi G. Adverse Drug Reactions reporting: Attitudes and perceptions of medical practitioners. Asian J Pharm Clin Res. 2009; 2:10-4.

Ryan C, Ross S, Davey P, Duncan E, Fielding S, Francis JJ, Johnston M, Ker J, Lee AJ, MacLeod MJ, Maxwell S, McKay G, McLay J, Webb DJ, Bond C. Junior doctors' perceptions of their self-efficacy in prescribing, their prescribing errors and the possible causes of errors. British Journal of Clinical Pharmacology. 2013; 76(6):980-87. https://www. ncbi.nlm.nih.gov/pmc/articles/PMC3845322/.

Society of Pharmacovigilance, India. [Updated on 2008 Dec 3]. Available from: http://www.medbeats.com/sopi.html.

Sada O, Melkie A, Shibeshi W. Medication prescribing errors in the medical intensive care unit of Tikur Anbessa Specialized Hospital, Addis Ababa, Ethiopia. BMC Research Notes. 2015; 8(1):448. doi: 10.1186/ s13104-015-1435-y.

Sheikh D, Mateti U, Kabekkodu S, Sanal T. Assessment of medication errors and adherence to WHO prescription writing guidelines in a tertiary care hospital. Future Journal of Pharmaceutical Sciences. 2017; 3(1):60-64.

Starmer AJ, Spector ND, West DC, Srivastava R, Sectish TC, Landrigan CP. I-PASS Study Group. Integrating Research, Quality Improvement, and Medical Education for Better Handoffs and Safer Care: Disseminating, Adapting, and Implementing the I-PASS Program. Joint Commission Journal on Quality and Patient Safety. 2017; 43(7):319-29. doi: 10.1016/j.jcjq.2017.04.001. Epub 2017 Jun 1.

Wilson D, McArtney R, Newcombe R, McArtney R, Gracie J, Kirk C, Stuart AG. Medication errors in paediatric practice: insights from a continuous quality improvement approach. European Journal of Pediatrics. 1998; 157(9):769-74. https://www.ncbi.nlm.nih.gov/pubmed/9776539.

Woolf SH, Kuzel AJ, Dovey SM, Phillips RL. A string of mistakes: the cascade analysis in describing, counting, and preventing 
medical errors. Ann Fam Med. 2004; 2:317-26. https://www.ncbi.nlm.nih. gov/pubmed/15335130.

Zakharov S, Tomas N, Pelclova D. Medication errors-an enduring problem for children and elderly patients. Upsala Journal of Medical Sciences. 2012; 117(3):309-17.

WHO. Reporting and learning systems for medication errors: The role of pharmacovgilence centers. 2014 [cited 30 September 2017]. Available from http://apps.who.int/medicinedocs/documents/s21625en/ s21625en.pdf.

\section{How to cite this article:}

Mugada V, Devineni RC, Pendyala RM, Vempati D, Kuchi S. Categorization, Appraisal, and Reporting of Medication Errors Ascertained in Medical Ward of Tertiary Care Hospital. J App

Pharm Sci, 2018; 8(05): 109-114. 